\title{
Effects of Thermal Exposure and Test Temperature on Structure Evolution and Hardness/Viscosity of an Iron-Based Metallic Glass
}

\author{
A. SHAMIMI NOURI, Y. LIU, and J.J. LEWANDOWSKI
}

High-temperature microhardness testing on drop-cast ingots of fully amorphous $\mathrm{Fe}_{48} \mathrm{Mo}_{14}$ $\mathrm{Cr}_{15} \mathrm{Y}_{2} \mathrm{C}_{15} \mathrm{~B}_{6}$ was performed in order to determine the behavior and structure evolution of this Fe-bulk metallic glass under a variety of different test conditions. The effects of changes in test temperature on the microhardness/strength were determined over the temperature range from room temperature to $620^{\circ} \mathrm{C}$. Although high (e.g., > $12 \mathrm{GPa}$ ) microhardness was exhibited at room temperature, significant hardness reductions were exhibited near $T_{g}$. In addition, the effect of exposure time (up to 300 minutes) at elevated temperature on the evolution of microhardness/strength was also evaluated for selected temperatures between $25^{\circ} \mathrm{C}$ and $620^{\circ} \mathrm{C}$. The microhardness results were complemented with X-ray diffraction (XRD), conventional transmission electron microscopy (TEM), and an in-situ heating TEM study in order to evaluate any structural evolution that could explain the large differences in hardness evolution under different test conditions.

DOI: $10.1007 / \mathrm{s} 11661-008-9615-1$

(c) The Minerals, Metals \& Materials Society and ASM International 2008

\section{INTRODUCTION}

BY their very nature, amorphous alloys exist in a metastable condition. Considerable research has been conducted over the last number of decades in order to understand their physical behavior, such as structural relaxation and crystallization, upon annealing within the supercooled liquid region. On the atomic scale, the rearrangement of atoms is often described by free volume model. ${ }^{[1,2]}$ Based on this model, the amount and change of excess free volume can strongly affect the physical and mechanical properties (i.e., viscosity, flow, and fracture). In some cases, the thermal annealing that produces devitrification, especially nanocrystallization, can be useful for improving the mechanical, magnetic, and some other properties. ${ }^{[3,4]}$ Characterization of the mechanical response that accompanies the loss of free volume or devitrification can help to better understand the behavior of these glasses and how such properties are related to atomic scale structural rearrangements.

A. SHAMIMI NOURI, Graduate Assistant, and J.J. LEWANDOWSKI, Leonard Case Professor of Engineering, are with Department of Materials Science and Engineering, Case Western Reserve University, Cleveland, OH 44106. Contact e-mail: JJL3@ case. edu Y. LIU, formerly Research Associate, Department of Materials Science and Engineering, Case Western Reserve University, is TEM Lab Manager, with The Department of Chemistry, Wayne State University, Detroit, MI 48202.

This article is based on a presentation given in the symposium entitled "Iron-Based Amorphous Metals: An Important Family of High-Performance Corrosion-Resistant Materials," which occurred during the MSandT meeting, September 16-20, 2007, in Detroit, Michigan, under the auspices of The American Ceramics Society (ACerS), The Association for Iron and Steel Technology (AIST), ASM International, and TMS
From an application standpoint, the thermal stability of bulk metallic glasses (BMGs) is one of the most important properties influencing their potential adaptation in various structural applications or as coatings. For example, the Fe-based BMGs are of great interest because of their combination of exceptional strength $(\approx 4 \mathrm{GPa})$ and very high hardness (i.e., 11 to $13 \mathrm{GPa})$ with excellent corrosion resistance. ${ }^{[5]}$ Recently, various coating techniques (e.g., high velocity oxygen fuel (HVOF), plasma spray, cold spray, etc.) have been used to create amorphous coatings in which the BMG particles/powders undergo significant deformation as well as thermal hysteresis. ${ }^{[6]}$ Therefore, the thermal stability and effects of changes in test temperature on the flow behavior are vitally important to both the processing and subsequent properties of these coatings.

A convenient way to quickly assess the effects of changes in test temperature (and time at temperature) on the hardness/strength is to conduct microhardness tests over a range of temperatures, as has been reported elsewhere for various BMGs. ${ }^{[7-9]}$

In the present study, the effect of changes in test temperature on the microhardness of drop-cast $\mathrm{Fe}_{48} \mathrm{Mo}_{14} \mathrm{Cr}_{15} \mathrm{Y}_{2} \mathrm{C}_{15} \mathrm{~B}_{6}$ bulk metallic glass is investigated. In addition, the effects of exposure times ( $\leq 5$ hours) at elevated temperatures on the evolution of microhardness are presented. Both X-ray diffraction (XRD) and in-situ hot stage transmission electron microscopy (TEM) were conducted, in addition to conventional TEM on as-cast samples annealed for various time and temperature combinations in order to document any structure evolution that could be responsible for some of the significant changes in microhardness. These changes in microhardness with exposure time at elevated temperature were correlated with the structure evolution and were used to 
rationalize the structure-induced changes to the viscosity of the glass that could produce such changes to the microhardness.

\section{EXPERIMENTAL PROCEDURES}

Fully amorphous $\mathrm{Fe}_{48} \mathrm{Mo}_{14} \mathrm{Cr}_{15} \mathrm{Y}_{2} \mathrm{C}_{15} \mathrm{~B}_{6}$ rods with dimensions of $5 \mathrm{~mm}$ in diameter and $75 \mathrm{~mm}$ in length were produced at Oak Ridge National Laboratory in the form of drop-cast ingots. Multiple samples from each drop-cast rod were cut into final dimensions of $5 \mathrm{~mm}$ in diameter $\times 5 \mathrm{~mm}$ in length for hot microhardness testing. All samples were first examined by XRD on a Scintag X1 (Scintag, Inc., Cupertino, CA) $\left(\mathrm{Cu} K_{\alpha}\right)$ and confirmed as fully amorphous. Sample surfaces were then polished flat and parallel to 6- $\mu \mathrm{m}$ finish prior to any testing. A Buehler Micromet (BUEHLER Ltd., Lake Bluff, IL) 3 microhardness tester with a diamond Vickers indenter was used to determine the microhardness at room temperature on the transverse cross sections of the samples.

Microhardness testing was also performed at temperatures up to and beyond the glass transition temperature, determined between $560{ }^{\circ} \mathrm{C}$ and $575^{\circ} \mathrm{C}$ from previous differential scanning calorimeter (DSC), ${ }^{[10]}$ using a Nikon $\mathrm{QM}^{*}$ high-temperature microhardness

*Nikon QM is a trademark of Nikon Inc., Tokyo, Japan.

testing machine with a diamond Vickers indenter. An indentation load of 500 grams and a loading time of 15 seconds were used for all tests, producing a hardness number under relatively low loading rate (i.e., low strain rate) conditions. The details of the high-temperature tests performed on each sample utilized the following procedures to first determine the effects of changes in temperature on the microhardness, followed by separate studies on the evolution of hardness at a fixed temperature for different exposure times.

In the first series of tests, the sample and indenter were separately heated to the same temperature at a rate of approximately $10^{\circ} \mathrm{C} / \mathrm{min}$ using separate furnaces inside the Nikon QM and the microhardness was measured on one sample at each of the temperatures $150{ }^{\circ} \mathrm{C}, 300{ }^{\circ} \mathrm{C}, 400{ }^{\circ} \mathrm{C}, 500{ }^{\circ} \mathrm{C}, 562{ }^{\circ} \mathrm{C}, 575{ }^{\circ} \mathrm{C}, 600{ }^{\circ} \mathrm{C}$, and $620^{\circ} \mathrm{C}$. At least three indents were made at each test temperature on one sample prior to changing the temperature for the next set of indentations. The temperature variation monitored during the indentation was $\pm 3{ }^{\circ} \mathrm{C}$ and the specimen was held at temperature for 3 minutes prior to indentation. The indents were each measured three times after cooling to room temperature.

The second set of tests were performed on separate as-cast samples in order to determine the effects of different exposure times on the evolution of microhardness. In these cases, a total of 8 separate samples were tested individually at different temperatures. Each sample and the indenter were heated directly to some higher temperature at a rate of approximately $10{ }^{\circ} \mathrm{C} / \mathrm{min}$ using separate furnaces inside the Nikon QM machine.
Microhardness measurements were taken at a variety of exposure times, including: $0,1,2,5,10,30$, and 60 minutes. The microhardness of some samples was also taken after 120,150, 180, 240, and 300 minutes. The temperatures used for the various exposures on the eight separate samples were $150{ }^{\circ} \mathrm{C}, 300{ }^{\circ} \mathrm{C}, 400{ }^{\circ} \mathrm{C}$, $500{ }^{\circ} \mathrm{C}, 562{ }^{\circ} \mathrm{C}, 575^{\circ} \mathrm{C}, 600{ }^{\circ} \mathrm{C}$, and $620^{\circ} \mathrm{C}$.

The room-temperature microhardness was additionally performed on all samples after all thermal exposures described previously, while hardness was also recorded during the excursion from high temperature back to room temperature for the following temperatures: $562{ }^{\circ} \mathrm{C}, 575^{\circ} \mathrm{C}, 600{ }^{\circ} \mathrm{C}$, and $620^{\circ} \mathrm{C}$. Particular note was made of any cracks originating from the edges of the microhardness indents for any of the conditions.

Structure evolution was determined via conventional TEM on samples exposed to $500{ }^{\circ} \mathrm{C}, 600{ }^{\circ} \mathrm{C}$, and $620^{\circ} \mathrm{C}$ for 300,285 , and 150 minutes, respectively. In these cases, the tested samples were first sliced to thicknesses between 0.5 and $0.8 \mathrm{~mm}$ using a low-speed diamond saw. The slices were then carefully ground to approximately $50 \mu \mathrm{m}$ using a dimpling grinder. Final thinning was conducted by ion-beam milling at $5 \mathrm{kV}$ with the milling angle at $5 \mathrm{deg}$. Samples were examined using a JEOL**-

**JEOL is a trademark of Japan Electron Optics Ltd., Tokyo.

2010 FasTEM, operated at $200 \mathrm{kV}$. In addition to these conventional TEM studies, in-situ heating experiments were conducted inside the TEM using a double-tilt heating stage (GATAN model 652, Gatan Inc., Pleasanton, CA) with the temperature controlled precisely by a SmartSet Hot Stage controller (GATAN model 901, Gatan Inc., Pleasanton, CA).

The in-situ TEM studies were conducted in order to study the devitrification process in more detail as it evolved. As an example, an as-cast sample was heated to $600{ }^{\circ} \mathrm{C}$ in $100{ }^{\circ} \mathrm{C}$ increments with a heating rate of $10{ }^{\circ} \mathrm{C} / \mathrm{min}$. The TEM micrographs and diffraction patterns were taken at each $100{ }^{\circ} \mathrm{C}$ increment, while the total heating time to $600{ }^{\circ} \mathrm{C}$ was 1 hour. In addition, three other as-cast samples were prepared and heated directly to $500{ }^{\circ} \mathrm{C}, 575{ }^{\circ} \mathrm{C}$, and $620^{\circ} \mathrm{C}$, respectively, with a heating rate of $100{ }^{\circ} \mathrm{C} / \mathrm{min}$. After reaching these desired temperatures, these separate samples were held at these temperatures for 2 hours to document any microstructural evolution. The samples were heated to the desired temperatures usually within 5 to 7 minutes with temperature stabilization within 2 to 3 additional minutes. The electron beam was only turned on for taking photos in order to avoid any beam heating effects.

\section{RESULTS}

The XRD of the as-cast $\mathrm{Fe}_{48} \mathrm{Mo}_{14} \mathrm{Cr}_{15} \mathrm{Y}_{2} \mathrm{C}_{15} \mathrm{~B}_{6}$ revealed the lack of long-range order, typical in metallic glasses. No cracking was observed around the microhardness indentations for the as-cast samples. This indicates that the $\mathrm{Fe}_{48} \mathrm{Mo}_{14} \mathrm{Cr}_{15} \mathrm{Y}_{2} \mathrm{C}_{15} \mathrm{~B}_{6}$ does 




Fig. 1-Effects of changes in test temperature on microhardness of $\mathrm{Fe}_{48} \mathrm{Mo}_{14} \mathrm{Cr}_{15} \mathrm{Y}_{2} \mathrm{C}_{15} \mathrm{~B}_{6}$.

possess some level of damage tolerance in compression, as ceramics tested under similar conditions typically exhibit cracks that emanate from the corners of the microhardness indentations. ${ }^{[12]}$ Other work $^{[13]}$ has shown that chemistry changes to the elastic constants produce Fe-based BMGs with different degrees of compressive plasticity, while toughness values are similarly correlated with the elastic constants elsewhere. ${ }^{[14]}$

\section{A. Effects of Test Temperature on Microhardness}

Figure 1 shows the effects of changes in test temperature on microhardness of one sample of $\mathrm{Fe}_{48} \mathrm{Mo}_{14}$ $\mathrm{Cr}_{15} \mathrm{Y}_{2} \mathrm{C}_{15} \mathrm{~B}_{6}$. Hardness is plotted as Vickers hardness number (VHN) in $\mathrm{GPa}$ as well as $\mathrm{kg} / \mathrm{mm}^{2}$. Figure 2 plots the same data as estimated compressive strength, using the relation strength $=\mathrm{VHN} / 3$. The room-temperature microhardness exceeds $1200 \mathrm{VHN}$, which converts to an estimated compressive strength of $4000 \mathrm{MPa}$, well in excess of most crystalline materials and consistent with the compressive strength reported on other Fe-based BMGs. ${ }^{[13]}$ Significant softening is observed upon approaching the glass transition temperature. The microhardness near $T_{g}$ is significantly lower (e.g., $\mathrm{VHN}=20$ ) under these loading conditions, producing an estimated compressive strength of only $200 \mathrm{MPa}$. A similar reduction in hardness/ strength has been reported for a number of metallic glass systems ${ }^{[7-9,15]}$ upon approaching $T_{g}$ and is generally consistent with the behavior of amorphous metal systems. Microhardness levels in excess of VHN 1000 (i.e., estimated compressive strengths $>3250 \mathrm{MPa}$ ) were obtained for temperatures up to $400{ }^{\circ} \mathrm{C}$, with the large drop in microhardness/strength occurring between $500{ }^{\circ} \mathrm{C}$ and $600{ }^{\circ} \mathrm{C}$. After these thermal excursions, the microhardness values obtained at room temperature were in excess of that measured on the starting material (i.e., $>1200 \mathrm{VHN}$ ), indicative of irreversible changes (e.g., microstructure evolution, and devitrification). Similar changes to hardness have been reported after exposure to high temperatures for other metallic glass systems. ${ }^{[7,16]}$

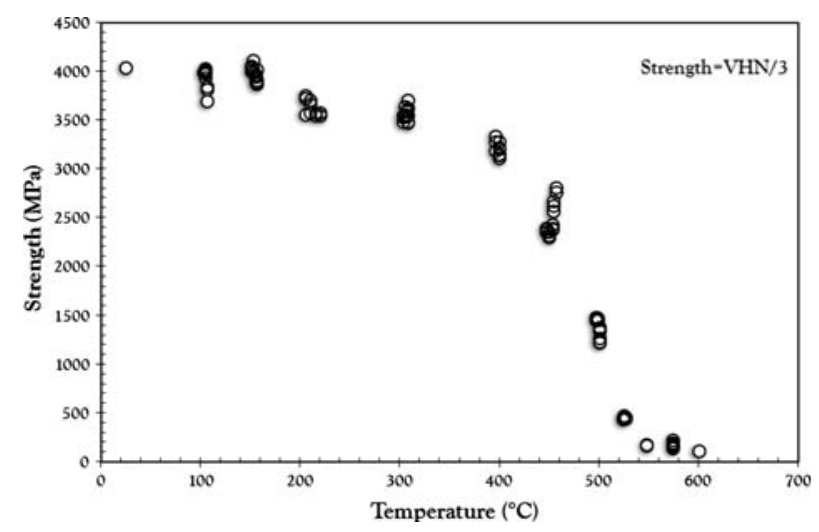

Fig. 2-Effects of changes in test temperature on estimated strength obtained microhardness of $\mathrm{Fe}_{48} \mathrm{Mo}_{14} \mathrm{Cr}_{15} \mathrm{Y}_{2} \mathrm{C}_{15} \mathrm{~B}_{6}$. Estimated strength calculated as VHN/3.

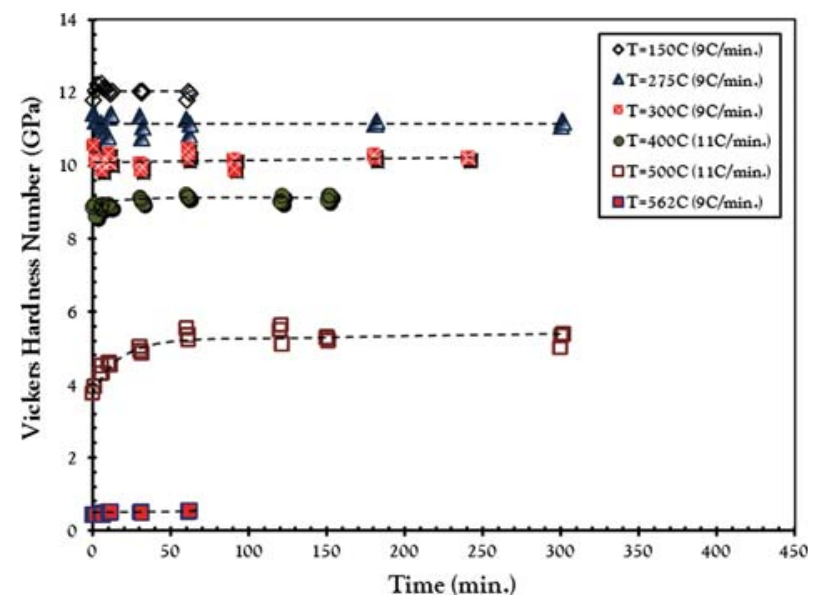

Fig. 3-Effect of exposure time on microhardness evolution for separate samples held at $150{ }^{\circ} \mathrm{C}, 275^{\circ} \mathrm{C}, 300{ }^{\circ} \mathrm{C}, 400{ }^{\circ} \mathrm{C}, 500{ }^{\circ} \mathrm{C}$, and $562{ }^{\circ} \mathrm{C}$ for times up to $300 \mathrm{~min}$. Heating rates used shown in parentheses.

\section{B. Thermal Exposure Effects on Microhardness}

Figure 3 shows the effect of exposure time on microhardness (plotted in GPa) evolution obtained on six separate samples held at $150^{\circ} \mathrm{C}, 275^{\circ} \mathrm{C}, 300^{\circ} \mathrm{C}$, $400{ }^{\circ} \mathrm{C}, 500{ }^{\circ} \mathrm{C}$, and $562{ }^{\circ} \mathrm{C}$, respectively, for times up to 300 minutes. The microhardness/strength at $150{ }^{\circ} \mathrm{C}$ is still essentially the same as that obtained at room temperature (e.g., $1200 \mathrm{~kg} / \mathrm{mm}^{2}, 12 \mathrm{GPa}$, and estimated strength $=4000 \mathrm{MPa}$ ). Initial values of microhardness at $275^{\circ} \mathrm{C}, 300{ }^{\circ} \mathrm{C}, 400{ }^{\circ} \mathrm{C}, 500{ }^{\circ} \mathrm{C}$, and $562{ }^{\circ} \mathrm{C}$ are 11 , $10,9,5.5$, and $0.7 \mathrm{GPa}$, respectively, and the trends show very little effect of exposure time on microhardness evolution at temperatures up to $562{ }^{\circ} \mathrm{C}$, although a slight change in hardness for times up to 30 minutes was obtained for the sample held at $500{ }^{\circ} \mathrm{C}$. Figure 4 shows the effect of exposure time on microhardness evolution at $562{ }^{\circ} \mathrm{C}, 575^{\circ} \mathrm{C}, 600{ }^{\circ} \mathrm{C}$, and $620^{\circ} \mathrm{C}$, respectively, for times up to 150 minutes. The microhardness/strength at $600{ }^{\circ} \mathrm{C}$ (e.g., $10 \mathrm{~kg} / \mathrm{mm}^{2}, 0.1 \mathrm{GPa}$, and estimated strength $50 \mathrm{MPa}$ ) is significantly reduced from the room-temperature values, although the microhardness 


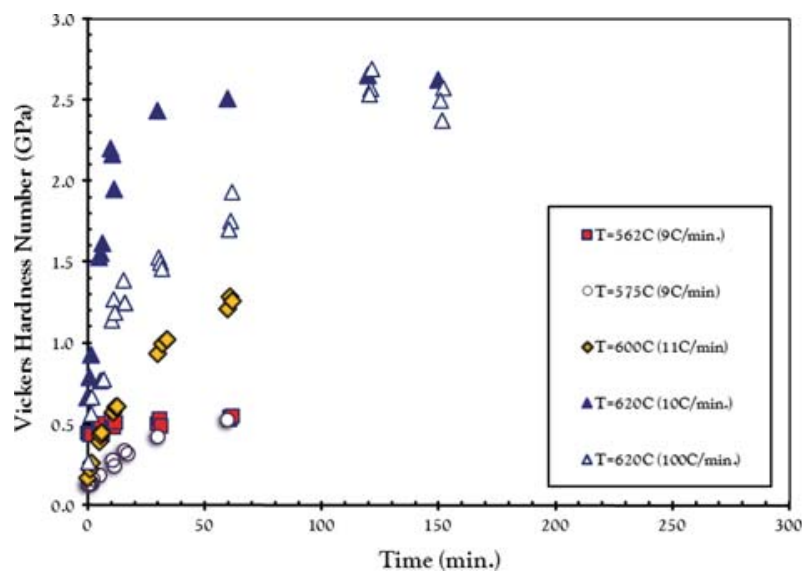

Fig. 4 -Effect of exposure time on microhardness evolution for separate samples held at $562{ }^{\circ} \mathrm{C}, 575^{\circ} \mathrm{C}, 600{ }^{\circ} \mathrm{C}$, and $620^{\circ} \mathrm{C}$ for times up to $285 \mathrm{~min}$. Heating rates used shown in parenthesis.

changes from only 0.17 to $1.25 \mathrm{GPa}$ with exposure times up to 60 minutes at $600{ }^{\circ} \mathrm{C}$. The same trend is observed at $620^{\circ} \mathrm{C}$, where the initial microhardness changes rapidly from only 0.15 to $2.7 \mathrm{GPa}$ with exposure times up to 150 minutes.

\section{Structure Evolution-Conventional TEM of Thermally-Exposed Samples}

The TEM observations of as-cast $\mathrm{Fe}_{48} \mathrm{Mo}_{14}$ $\mathrm{Cr}_{15} \mathrm{Y}_{2} \mathrm{C}_{15} \mathrm{~B}_{6}$ ingots revealed the presence of two different domains, as shown in Figure 5(a). The two domains labeled "white" and "gray" are also more apparent for samples exposed to $500{ }^{\circ} \mathrm{C}$ (Figure 5(b)) and those devitrified at temperatures above $T_{g}$, as shown in Figure 5(c) $\left(600^{\circ} \mathrm{C}\right)$. Table I summarizes the energy dispersive spectrum obtained from these two different domains for the as-cast and thermally-exposed samples. Compared with the gray domain, the white domain contains more $\mathrm{Y}$, less $\mathrm{Fe}$ and $\mathrm{Cr}$, and similar amounts of Mo. The mean size of the white domains in samples exposed to $500{ }^{\circ} \mathrm{C}$ and $600{ }^{\circ} \mathrm{C}$ were estimated to be $52 \pm 5 \mathrm{~nm}$ and $62 \pm 5 \mathrm{~nm}$, respectively, although the low contrast of white domains may lead to an overes- timate of their actual size due to the difficulty of accurately defining the white/gray boundaries.

Figure 6 shows TEM bright-field images in the samples exposed to $600{ }^{\circ} \mathrm{C}$ for 60 minutes (Figure $6(\mathrm{a})$ ), $600{ }^{\circ} \mathrm{C}$ for 285 minutes (Figure $6(\mathrm{~b})$ ), and $620^{\circ} \mathrm{C}$ for $150 \mathrm{~min}$ utes (Figure 6(c)). Crystalline phases are clearly evident in the gray domain, whereas the white domain appears to be amorphous. In the sample exposed to $620^{\circ} \mathrm{C}$ for 150 minutes, the nanocrystalline regions in the devitrified areas have an average size of $14 \pm 2 \mathrm{~nm}$. Figure 7 shows high-resolution electron microscopy (HREM) images of the samples exposed to $620^{\circ} \mathrm{C}$ for 150 minutes (Figure $7(\mathrm{a})$ ) and $500{ }^{\circ} \mathrm{C}$ for 300 minutes (Figure 7(b)), respectively. Lattice images are evident in the sample exposed to $620^{\circ} \mathrm{C} / 150 \mathrm{~min}$ while only very short-range order is exhibited in the sample exposed to $500{ }^{\circ} \mathrm{C} /$ 300 min indicating that the sample exposed to $500{ }^{\circ} \mathrm{C}$ for 300 minutes is predominantly amorphous. The structural changes in samples presently annealed at $600{ }^{\circ} \mathrm{C}$ and $620^{\circ} \mathrm{C}$ are generally consistent with DSC measurements reported by others ${ }^{[1]}$ that provide evidence of structure evolution with time at these temperatures.

\section{Structure Evolution In-Situ TEM Observations}

The results of the in-situ heating experiments in the TEM were broadly consistent with the conventional TEM results outlined previously. Figure 8 shows a sequence of TEM images taken from one sample at the temperatures shown, using a heating rate of $10{ }^{\circ} \mathrm{C} / \mathrm{min}$ and imaging every $100{ }^{\circ} \mathrm{C}$. Again, there is evidence of the white and gray domains, while the images further indicate that the as-cast $\mathrm{Fe}_{48} \mathrm{Mo}_{14} \mathrm{Cr}_{15} \mathrm{Y}_{2} \mathrm{C}_{15} \mathrm{~B}_{6}$ exhibited a few crystalline regions in the gray domains when examined at $600{ }^{\circ} \mathrm{C}$. These small crystalline regions grew to about 50 to $100 \mathrm{~nm}$. Crystallization in the gray domains can be more clearly seen in a separate sample heated to $620^{\circ} \mathrm{C}$ with the heating rate of $100{ }^{\circ} \mathrm{C} / \mathrm{min}$, shown in Figure 9. Figure 10 shows another set of photos for the Fe-BMG sample heated directly to $620{ }^{\circ} \mathrm{C}$ in about 6 to 7 minutes with a heating rate of $100{ }^{\circ} \mathrm{C} / \mathrm{min}$ and held for the times shown. Both Figures 6 and 9 illustrate that preferential crystallization occurs in the gray domains as soon as the sample is stabilized at
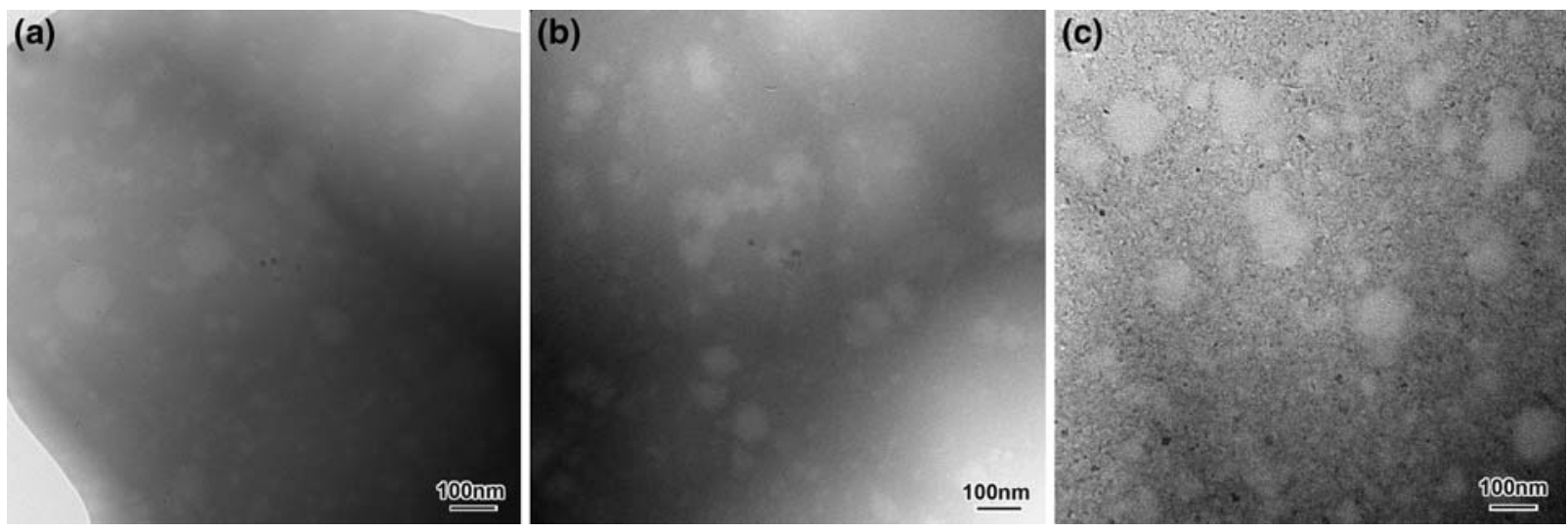

Fig. 5-TEM bright-field images from separate Fe-base BMG samples (a) as-received and (b) exposed to $500{ }^{\circ} \mathrm{C}$ for 300 min, not devitrified (c) exposed to $600{ }^{\circ} \mathrm{C}$ for $285 \mathrm{~min}$, the sample already devitrified. 
Table I. Comparison of TEM-EDS Analyses of 'Gray' and 'White' Domains in As-received and Thermally Exposed Samples

\begin{tabular}{|c|c|c|c|c|c|c|c|c|}
\hline \multirow[b]{2}{*}{ Sample } & \multicolumn{2}{|c|}{$\mathrm{Fe}$} & \multicolumn{2}{|c|}{ Mo } & \multicolumn{2}{|c|}{$\mathrm{Cr}$} & \multicolumn{2}{|c|}{$\mathrm{Y}$} \\
\hline & $\begin{array}{c}\text { Gray } \\
\text { Domain }\end{array}$ & $\begin{array}{c}\text { White } \\
\text { Domain }\end{array}$ & $\begin{array}{c}\text { Gray } \\
\text { Domain }\end{array}$ & $\begin{array}{c}\text { White } \\
\text { Domain }\end{array}$ & $\begin{array}{c}\text { Gray } \\
\text { Domain }\end{array}$ & $\begin{array}{l}\text { White } \\
\text { Domain }\end{array}$ & $\begin{array}{c}\text { Gray } \\
\text { Domain }\end{array}$ & $\begin{array}{l}\text { White } \\
\text { Domain }\end{array}$ \\
\hline As-received & 17.1 & 5.3 & 4.9 & 4 & 5.7 & 2.5 & 0.7 & 2.9 \\
\hline $500{ }^{\circ} \mathrm{C} / 300 \mathrm{~min}$ & 27.4 & 12.2 & 7.7 & 6.8 & 8.9 & 5.2 & 1 & 4.5 \\
\hline $620^{\circ} \mathrm{C} / 150 \mathrm{~min}$ & 43.5 & 21.8 & 12.1 & 12.7 & 14.3 & 9.5 & 1.6 & 8.6 \\
\hline
\end{tabular}
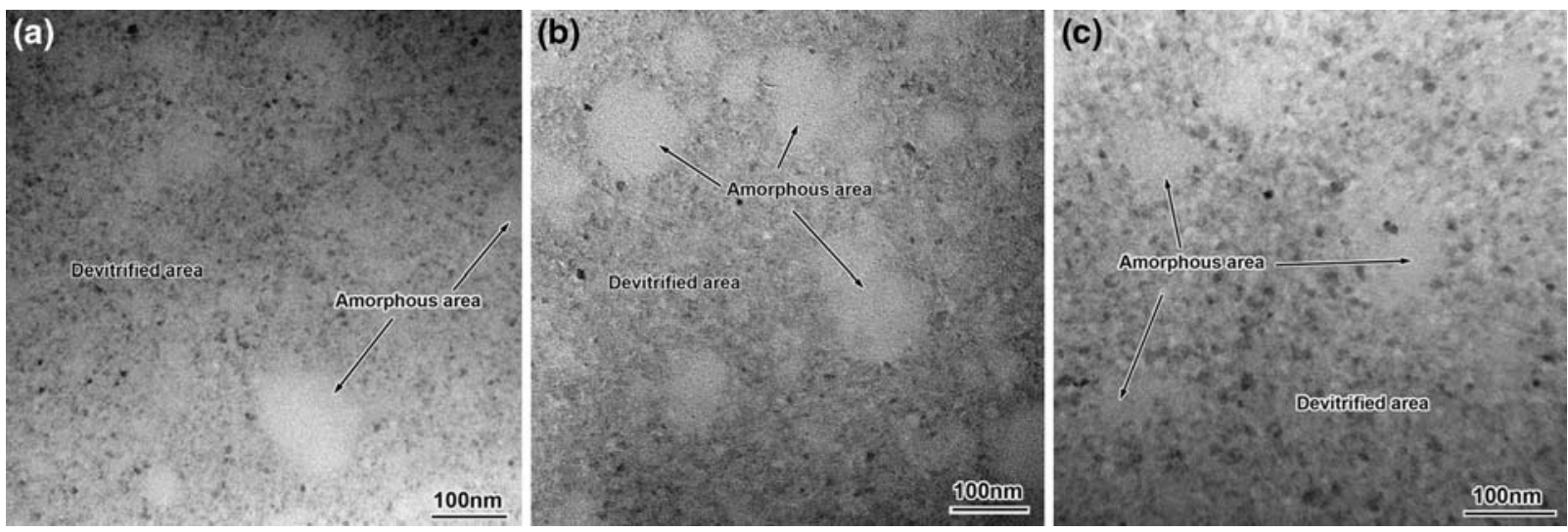

Fig. 6-TEM bright-field images from separate Fe-BMG samples exposed to (a) $600{ }^{\circ} \mathrm{C}$ for 60 min, (b) $600{ }^{\circ} \mathrm{C}$ for 285 min, and $(c) 620{ }^{\circ} \mathrm{C}$ for $150 \mathrm{~min}$. Devitrified area and amorphous areas are clearly seen.

$620{ }^{\circ} \mathrm{C}$, while the white domains remain amorphous. The crystalline regions are initially very small (e.g., $5 \mathrm{~nm}$ ) and then grow to several nanometers within about $30 \mathrm{~min}-$ utes as shown in Figures 10(b) through (f), after which no additional changes could be detected as shown in Figures 10(f) through (h). The presence of crystallization was also confirmed by examining the electron diffraction patterns.

Figure 11 shows another set of photos for the Fe-BMG sample heated directly to $575^{\circ} \mathrm{C}$ with the heating rate of $100{ }^{\circ} \mathrm{C} / \mathrm{min}$. As with the other cases, the sample preferentially was devitrified in the gray domains upon temperature stabilization at $575{ }^{\circ} \mathrm{C}$, while white domains remained amorphous. However, the grains/feature sizes in this sample are much smaller than that obtained in the sample heated to $620^{\circ} \mathrm{C}$, while the gray domains were not uniformly devitrified. Electron diffraction patterns corresponding to the different times of exposure after the sample stabilized at $575{ }^{\circ} \mathrm{C}$ revealed diffraction spots in the sample after 4 minutes exposure. In contrast to these observations, no crystallization was found during the entire heating process when the sample was heated to $500{ }^{\circ} \mathrm{C}$ with a heating rate of $100{ }^{\circ} \mathrm{C} / \mathrm{min}$. Electron diffraction images for exposure times up to 120 minutes similarly did not show any evidence of structure evolution at $500{ }^{\circ} \mathrm{C}$.

\section{DISCUSSION}

As mentioned previously, the gray domain, which contains less $\mathrm{Y}$, was devitrified when it was exposed to temperatures higher than $T_{g}$, while the white domain, which contains higher $\mathrm{Y}$, remained amorphous. This is consistent with the report that Yttrium additions improve the glass forming ability of Fe-based glasses, documented in a number of articles. ${ }^{[17-19]}$ The devitrified gray domains contain less $\mathrm{Y}$ than the amorphous gray domains, also consistent with the beneficial role of $\mathrm{Y}$ in the glass formability of these Fe-based metallic alloys.

Figure 12 shows the diffraction pattern obtained from an Fe-BMG sample annealed at $620^{\circ} \mathrm{C}$ for 132 minutes via in-situ heating in the TEM with the heating rate of $100{ }^{\circ} \mathrm{C} / \mathrm{min}$. The diffraction pattern was analyzed by carefully calibrating the camera length by using Al powder standard sample and can be indexed as either $(\mathrm{Fe}, \mathrm{Cr})_{23} \mathrm{C}_{6}$ (Figure 12(a)), which has a fcc crystal structure with the lattice parameter $a=1.0578 \mathrm{~nm}$, or $(\mathrm{Fe}, \mathrm{Cr})_{7} \mathrm{C}_{3}$ (Figure 12(b)), which has a hexagonal structure with lattice parameters $a=0.6882 \mathrm{~nm}$ and $c=0.454 \mathrm{~nm}^{[20]}$ However, HREM image of one particle in the Fe-BMG sample after hot microhardness exposure at $620^{\circ} \mathrm{C}$ with $10{ }^{\circ} \mathrm{C} / \mathrm{min}$ for 150 minutes is provided in Figure 13. The inset diffraction pattern is the fast Fourier transform (FFT) result from the particle. The diffraction pattern shows a $\langle 110\rangle$ type diffraction of fcc structure, which implies that the particle is $(\mathrm{Fe}, \mathrm{Cr})_{23} \mathrm{C}_{6}$. After calibrating the magnification by using a standard $\mathrm{Si}$ sample oriented to $\langle 110\rangle$ direction, the measured (111) spacing of particle is about $0.5955 \mathrm{~nm}$, which is close to the calculated $0.6107 \mathrm{~nm}$ of $(\mathrm{Fe}, \mathrm{Cr})_{23} \mathrm{C}_{6}$ reported in Reference 20 . The formation of $(\mathrm{Fe}, \mathrm{Cr})_{23} \mathrm{C}_{6}$ in similar alloys are also reported in other recent work. ${ }^{[18,19]}$ 
As shown previously, this Fe-BMG exhibits an inhomogeneous chemistry that devitrifies upon heating to temperatures near $T_{g}$. The inhomogeneous chemistry has a significant influence on the crystallization process
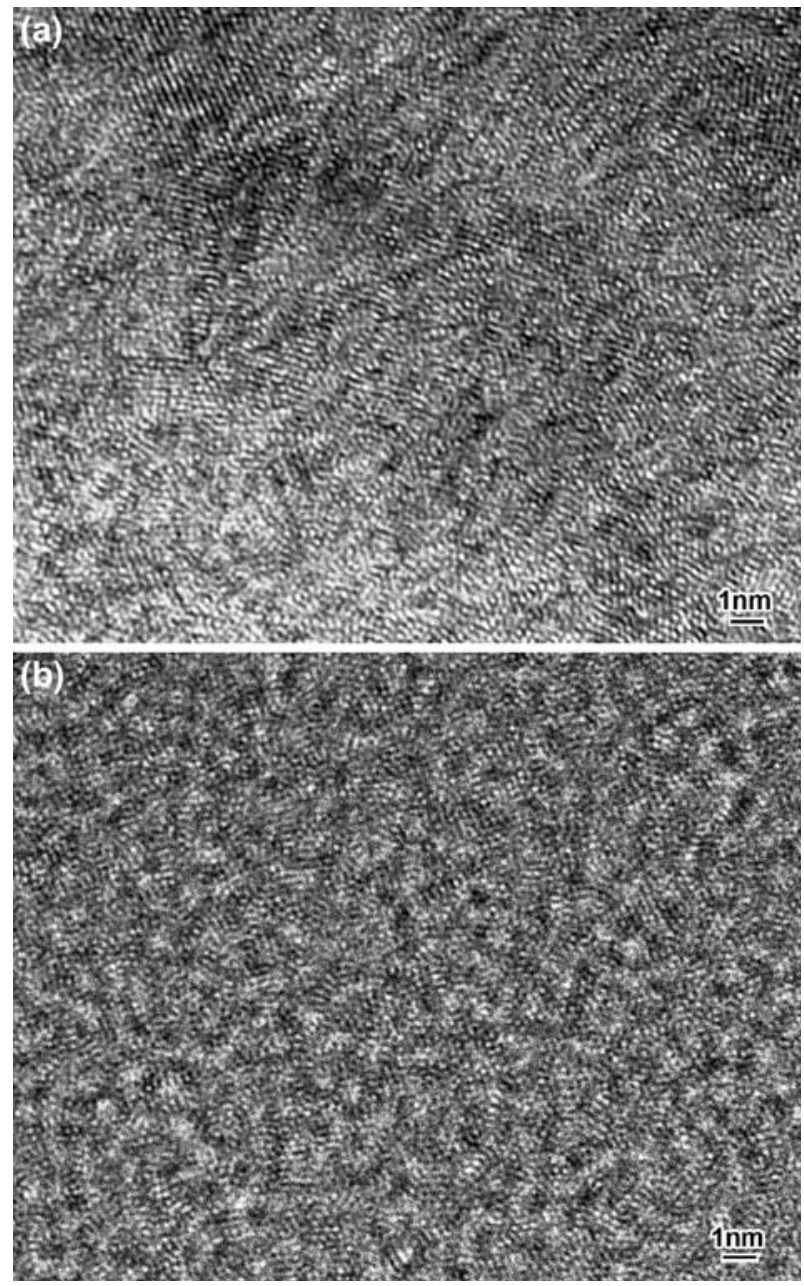

Fig. 7-HREM images of separate Fe-BMG samples exposed to $(a)$ $620{ }^{\circ} \mathrm{C}$ for $150 \mathrm{~min}$ and $\left(\right.$ b) $500{ }^{\circ} \mathrm{C}$ for $300 \mathrm{~min}$. Lattice images are evident in (a) and not in (b). at lower temperatures, thus destabilizing the BMG and ultimately producing nanocrystallization in the supercooled region, initially in the Y-lean regions. Such changes in the structure can significantly affect the viscosity of the glass, as has been reported for various BMGs by others. ${ }^{[21,22]}$ Constant load beam bending experiments at different temperatures are often used to measure the displacement rate of the beam and converted to apparent viscosity. In the absence of such experiments for the present materials, it is possible to estimate the compressive strengths obtained from the high-temperature microhardness results and convert to an apparent viscosity $(\eta)$ using $\eta=\frac{\sigma}{3 \dot{\varepsilon}}$ in which $\sigma$ and $\dot{\varepsilon}$ are flow stress and strain rate, respectively. ${ }^{[23]}$ The strain rates were estimated using the measured depth of the hardness indentations using a laser confocal microscope and loading time of 15 seconds for all tests. Estimated strain rates in the $10^{-5} / \mathrm{s}$ regime were obtained and assumed constant despite the changing properties of the material. This approach produces values for viscosity at

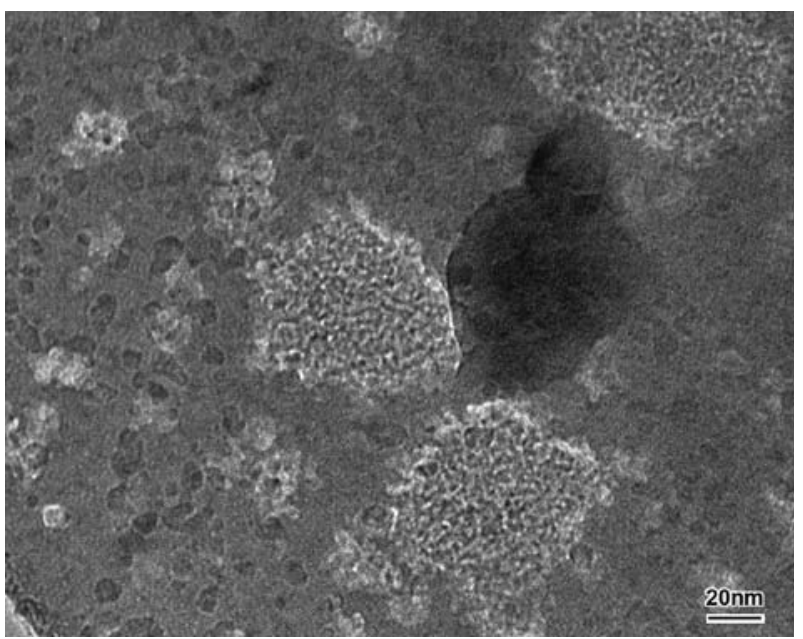

Fig. 9-Devitrified Fe-BMG at $620^{\circ} \mathrm{C}$ with the heating rate of $100{ }^{\circ} \mathrm{C} / \mathrm{min}$ for $150 \mathrm{~min}$. Devitrification started in the gray domain, which contains lower $\mathrm{Y}$
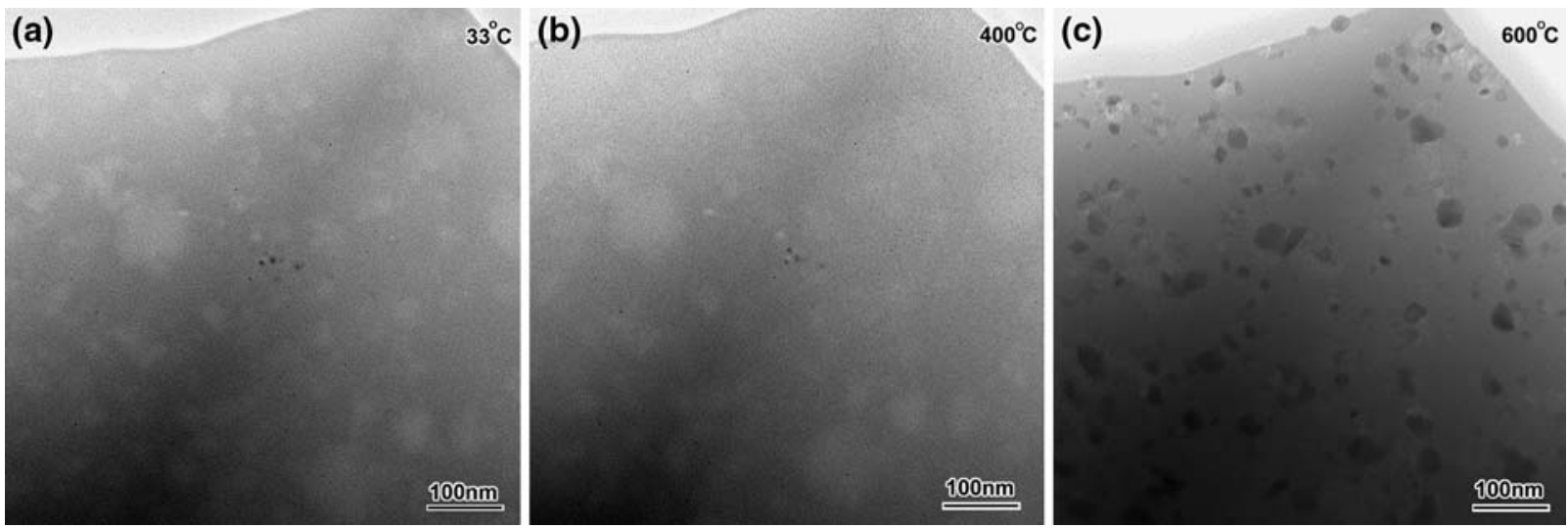

Fig. 8- In-situ heating TEM observation on the as-received Fe BMG (a) at $33{ }^{\circ} \mathrm{C},(b) 400{ }^{\circ} \mathrm{C}$, and $(c) 600{ }^{\circ} \mathrm{C}$. Significant structure evolution was not observed until the amorphous alloy reached $600{ }^{\circ} \mathrm{C}$. 

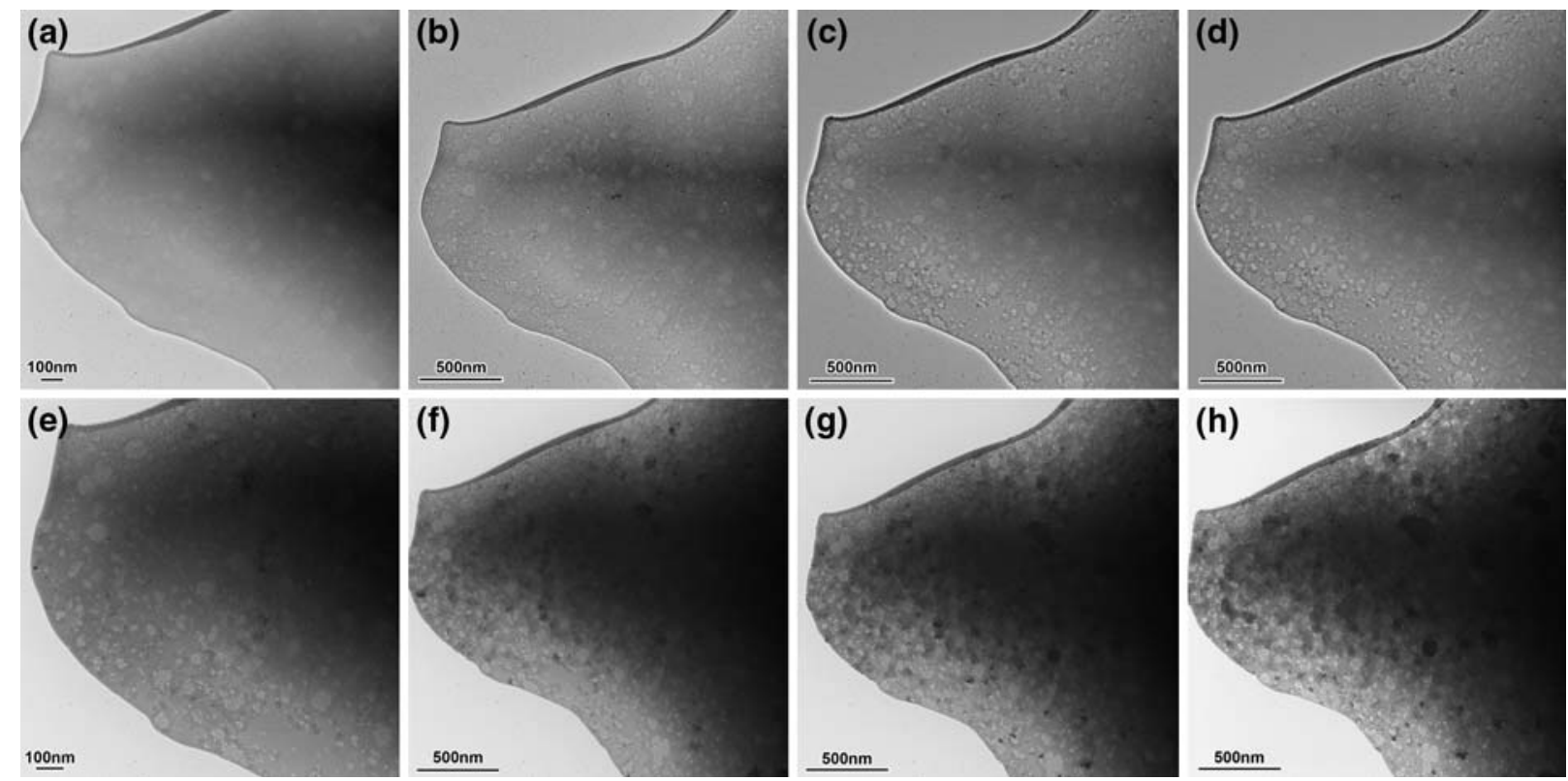

Fig. 10 - In-situ heating TEM observation on the as-received Fe-BMG after heating to $620^{\circ} \mathrm{C}$ with the rate of $100{ }^{\circ} \mathrm{C} / \mathrm{min}$ and stabilized $(a)$ at room temperature and $(b)$ after stabilization at $620^{\circ} \mathrm{C}$ with holding times of $(c) 3 \mathrm{~min},(d) 5 \mathrm{~min},(e) 9 \mathrm{~min},(f) 32 \mathrm{~min},(\mathrm{~g}) 61 \mathrm{~min}$, and $(h)$ $120 \mathrm{~min}$.


Fig. 11-In-situ heating TEM observation on the as-received Fe-BMG after heating to $575{ }^{\circ} \mathrm{C}$ with the rate of $100{ }^{\circ} \mathrm{C} / \mathrm{min}$ and stabilization $(a)$ at room temperature and after stabilization at (b) $22 \mathrm{~min},(c) 68 \mathrm{~min},(d) 125 \mathrm{~min}$, and (e) $145 \mathrm{~min}$.

$T_{g}\left(\right.$ e.g., $\left.\eta \approx 10^{10} \mathrm{~Pa} \cdot \mathrm{s}\right)$ similar to other measurements on a variety of metallic glasses ${ }^{[21,22,25,26]}$ using beam bending (or other) experiments. The effects of exposure time at temperature on the evolution of viscosity was linked to the evolution of structure with these changes in properties. $^{[24]}$ 



Fig. 12-Diffraction patterns obtained from the same Fe-BMG sample annealed at $620^{\circ} \mathrm{C}$ for $132 \mathrm{~min}$ via in-situ heating in TEM with the heating rate of $100{ }^{\circ} \mathrm{C} / \mathrm{min}$ : $(a)$ indexed as $(\mathrm{Fe}, \mathrm{Cr})_{23} \mathrm{C}_{6}$, which has a fcc crystal structure with lattice parameter $a=1.0578 \mathrm{~nm}$; and $(b)$ indexed as $(\mathrm{Fe}, \mathrm{Cr})_{7} \mathrm{C}_{3}$, which has a hexagonal structure with lattice parameters $a=0.6882 \mathrm{~nm}$ and $c=0.454 \mathrm{~nm}$

The calculated viscosities at $T<500{ }^{\circ} \mathrm{C}$ were essentially in the range of that obtained at room temperature (in $10^{13} \mathrm{~Pa} \cdot \mathrm{s}$ range) and the trends show very little effect of exposure time on viscosity change, consistent with the lack of structure evolution shown via XRD and TEM. A slight increase in calculated viscosity with exposure time was obtained at both $500{ }^{\circ} \mathrm{C}$ and $562{ }^{\circ} \mathrm{C}$, while more significant effects of increasing exposure time on the calculated viscosities for temperatures near $T_{g}$, in the supercooled liquid region, and near/at $T_{x} .{ }^{\left[{ }^{[4]}\right.}$ Examination of the data in Figure 4 also reveals a significant effect of initial heating rate to $620^{\circ} \mathrm{C}$ (i.e., $10^{\circ} \mathrm{C} / \mathrm{min}$ vs

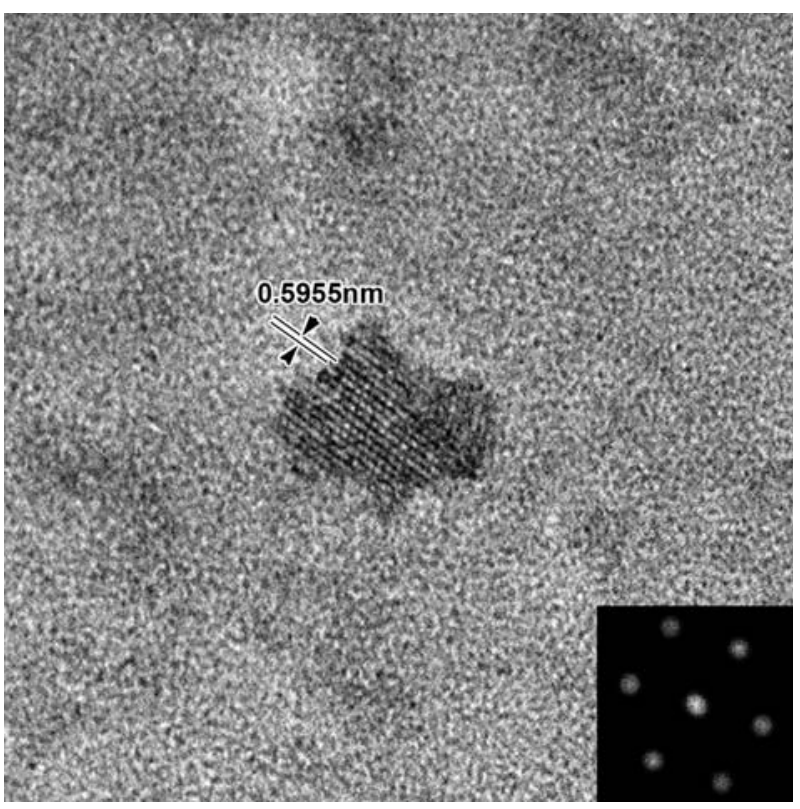

Fig. 13-HREM image of a carbide particle in the Fe-BMG sample given a thermal exposure of $620^{\circ} \mathrm{C}$ for 150 min during a hot hardness evolution study (heating rate: $10^{\circ} \mathrm{C} / \mathrm{min}$ ). The diffraction pattern obtained from the HREM by FFT indicates an fcc crystal structure, implying that the carbide is $(\mathrm{Fe}, \mathrm{Cr})_{23} \mathrm{C}_{6}$. The measured lattice parameter is close to the standard lattice parameter of $(\mathrm{Fe}, \mathrm{Cr})_{23} \mathrm{C}_{6}$. Magnification was calibrated by standard $\langle 110\rangle$ standard Si sample.

$100{ }^{\circ} \mathrm{C} / \mathrm{min}$ ) on the hardness evolution at $620^{\circ} \mathrm{C}$. Previous DSC work $^{[10]}$ and the present TEM results indicate that $620^{\circ} \mathrm{C}$ is very close to $T_{x}$ for this material, and rapid structure evolution is evident with increasing exposure time at this temperature. A faster heating rate to $620{ }^{\circ} \mathrm{C}$ will limit the amount of structure evolution that takes place during heating, thereby reducing the initial hardness (i.e., viscosity) determined at zero exposure time. Both samples exposed to $620{ }^{\circ} \mathrm{C}$ show rapid hardness increase with increasing exposure time, although the relative effect is greater for the sample heated to $620^{\circ} \mathrm{C}$ at $100^{\circ} \mathrm{C} / \mathrm{min}$. At 60 minutes exposure, the hardness values at $620^{\circ} \mathrm{C}$ for the two heating rates are very similar and do not change with further exposure times up to 300 minutes. The onset (i.e., determined via TEM and diffraction patterns) of crystallization occurs at relatively short times at these temperatures, roughly consistent with isothermal DSC results reported elsewhere. ${ }^{[10,11]}$

Interestingly, the changes in hardness for the sample held at $500{ }^{\circ} \mathrm{C}$ (Figure 3) occur in the absence of any detectable (i.e., via XRD or TEM) changes in structure. Similar changes in viscosity (i.e., without structure evolution) obtained in $\mathrm{Zr}$-based glasses ${ }^{[21,22]}$ have been attributed to structural relaxation and modeled using a stretched exponential function, followed by modeling of the equilibrium viscosity data using the Vogel-Fulcher-Tamman relationship. The viscosity changes calculated presently for the sample held at $500{ }^{\circ} \mathrm{C}$ are likely due to structural relaxation and were similarly fitted to a stretched exponential function. ${ }^{[24]}$ 




Fig. 14-Vickers microhardness as a function of temperature during cooling to room temperature after exposure to either $562{ }^{\circ} \mathrm{C}, 600{ }^{\circ} \mathrm{C}$, or $620^{\circ} \mathrm{C}$. " $\mathrm{X}$ " denotes hardness traverse obtained during heating of as-received $\mathrm{Fe}-\mathrm{BMG}$ to $550{ }^{\circ} \mathrm{C}$.

The stretching exponent $\beta$ is equal to 0.8 in the present work, ${ }^{[24]}$ very similar to that obtained in previous work $^{[21,22]}$ on the Zr-based glasses when no structure evolution was detected. Attempts at similar fitting exercises for the change in calculated viscosity obtained at different temperatures was not successful, most likely because of the extensive structure evolution, inhomogeneous chemistry, or a combination of these two features in the present materials. ${ }^{[24]}$

In addition to the microhardness tests conducted with increasing test temperatures (i.e., Figure 2) as well as those conducted for various exposure times at a given temperature (Figures 3 and 4), microhardness measurements were also conducted during the return to room temperature from the various exposure time/temperature combinations. Figure 14 summarizes a selection of the original VHN vs increasing test temperature data (shown previously in Figure 1) obtained on a fully amorphous sample taken to $550^{\circ} \mathrm{C}$. Included in Figure 14 are data obtained with decreasing test temperature after 60 minutes exposure to $562{ }^{\circ} \mathrm{C}, 600{ }^{\circ} \mathrm{C}$, and $620^{\circ} \mathrm{C}$. The decreasing test temperatures chosen for comparison, $550{ }^{\circ} \mathrm{C}, 500{ }^{\circ} \mathrm{C}, 400{ }^{\circ} \mathrm{C}, 300{ }^{\circ} \mathrm{C}$, and room temperature were chosen as the hardness of the amorphous BMG was previously determined at these temperatures. As shown above, each of the thermallyexposed samples exhibits a higher hardness (i.e., viscosity) than that of the amorphous material, except at $300{ }^{\circ} \mathrm{C}$ and room temperature for the sample held at $620^{\circ} \mathrm{C}$. This lower hardness obtained on the sample exposed to $620^{\circ} \mathrm{C}$ arises because of cracking around the microhardness indents, apparently due to embrittlement of the glass due to its higher viscosity, as discussed elsewhere. ${ }^{[2]}$ It is also clear that the higher temperature excursions (e.g., $620{ }^{\circ} \mathrm{C}$ vs $600{ }^{\circ} \mathrm{C}$ vs $562{ }^{\circ} \mathrm{C}$ ) produce a greater increase in the hardness (i.e., viscosity) over that of the fully amorphous sample as revealed in the microhardness tests taken with decreasing test temperature shown in Figure 14. As it is unlikely that additional structure evolution will occur with decreasing test temperature, particularly at temperatures below $550{ }^{\circ} \mathrm{C}$, these data further show the effects of evolved structure the hardness (i.e., viscosity) obtained during decreasing test temperatures.

\section{CONCLUSIONS}

Work has been conducted to determine the effects of various thermal excursions on the hardness/strength and thermal stability of $\mathrm{Fe}_{48} \mathrm{Mo}_{14} \mathrm{Cr}_{15} \mathrm{Y}_{2} \mathrm{C}_{15} \mathrm{~B}_{6}$. This glass exhibits exceptional hardness (i.e., $12 \mathrm{GPa}$ ) without cracking around the hardness indents at room temperature, while significant hardness/strength reductions were exhibited upon approaching the $T_{g}$. The evolution of hardness with exposure time at a variety of temperatures revealed essentially no change in hardness with exposure times for temperatures at or below $400{ }^{\circ} \mathrm{C}$ and exposure times up to 300 minutes in duration. Significant changes in hardness with exposure time were obtained at both $600{ }^{\circ} \mathrm{C}$ and $620{ }^{\circ} \mathrm{C}$, evidence of structural evolution and changes to the viscosity of the glass, which is reflected in the elevated hardness numbers obtained with increasing exposure time at these temperatures. Structural relaxation is the likely source of viscosity increase with exposure time at $500{ }^{\circ} \mathrm{C}$, since none of the techniques (XRD or TEM) revealed any structure evolution at $500{ }^{\circ} \mathrm{C}$ for times up to 300 minutes.

The TEM analysis revealed that there are two different domains, namely, white and gray domains, with different chemical compositions. The gray domain contains less Yttrium than in white domain, but more Iron and Chromium. The gray domains preferentially devitrified when the temperature reached and exceeded the $T_{g}$, while the white domains remained amorphous.

Diffraction pattern analysis from the particles in the devitrified samples indicated the formation of either $(\mathrm{Fe}, \mathrm{Cr})_{23} \mathrm{C}_{6}$ or $(\mathrm{Fe}, \mathrm{Cr})_{7} \mathrm{C}_{3}$. High-resolution TEM confirmed the formation of $(\mathrm{Fe}, \mathrm{Cr})_{23} \mathrm{C}_{6}$, consistent with reports in the literature. Thermal excursions near and above $T_{g}$ enabled nanocrystallization followed by primary crystallization, producing structures composed of crystals embedded in an amorphous matrix with different chemistry than the initial composition. Significant changes to the hardness were detected and attributed to changes in the viscosity due to a combination of structural relaxation, precipitation, and chemical inhomogeneity.

\section{ACKNOWLEDGMENTS}

The authors acknowledge the preparation and provision of the SAM 1651 samples by Oak Ridge National Laboratory, courtesy of William Peter and Craig Blue. This work is carried out under the United States Department of Energy (DOE), Corrosion and Materials Performance Cooperative (DOE Cooperative Agreement No. DE-FC28-04RW12252). The work is in support of the Defense Advanced Research Projects Agency, Defense Science Office, and the DOE 
Science \& Technology Program of the Office of the Chief Scientist, Office of Civilian Radioactive Waste Management program, for development of corrosion resistance of iron-based amorphous metal coatings under direction of Dr. J.C. Farmer at Lawrence Livermore National Laboratory. Approved for Public Release, Distribution Unlimited. Partial support from ONR-N00014-06-1-0492 through a sub-contract with University of Virginia is also gratefully acknowledged.

\section{REFERENCES}

1. F.A. Spaepen: Acta Metall., 1977, vol. 25, pp. 407-15.

2. A.S. Argon: Acta Metall., 1979, vol. 27, pp. 47-58.

3. A.L. Greer and E. Ma, eds., MRS Bull., 2007, vol. 32, pp. 611-19.

4. A.L. Greer: Science, 1995, vol. 267 (5206), pp. 1947-53.

5. J.R. Scully, A. Gebert, and J.H. Payer: J. Mater. Res., 2007, vol. $22(2)$, pp. 302-13.

6. D.J. Branagan, A.V. Sergueeva, and A.K. Mukherjee: Adv. Eng. Mater., 2006, vol. 8 (10), pp. 940-43.

7. J.J. Lewandowski, M. Shazly, and A. Shamimi Nouri: Scripta Mater., 2006, vol. 54 (3), pp. 337-41.

8. P. Wesseling, T.G. Nieh, W.H. Wang, and J.J. Lewandowski: Scripta Mater., 2004, vol. 51, pp. 151-54.

9. B.C. Ko, P. Wesseling, O.L. Vatamanu, G.J. Shiflet, and J.J. Lewandowski: Intermetallics, 2002, vol. 10, pp. 1099-1103.

10. K. Hildal, N. Sekido, and J.H. Perepezko: Intermetallics, 2006, vol. 14 , pp. 898-902.

11. K. Hildal, J.H. Perepezko, and L. Kaufman: Materials Science and Technology Conference Proceedings, pp. 361-69.
12. B.R Lawn and T.R. Wilshaw: Fracture of Brittle Solids, Cambridge University Press, New York, NY, 1975.

13. X.J. Gu, S.J. Poon, and G.J. Shiflet: J. Mater. Res., 2007, vol. 22 (2), pp. $344-51$.

14. J.J. Lewandowski, X.J. Gu, A. Shamimi Nouri, S.J. Poon, and G.J. Shiflet: Appl. Phys. Lett., 2008, vol. 92, pp. 091918-1-091918-3.

15. A.H. Vormelker, L.O. Vatamanu, L. Kecskes, and J.J. Lewandowski: Metall. Mater. Trans. A, 2008, vol. 39A, pp. 1922-34.

16. P. Wesseling, B.C. Ko, L.O. Vatamanu, G.J. Shiflet, and J.J. Lewandowski: Metall. Mater. Trans. A, 2008, vol. 39A, pp. 1935-41.

17. Z.P. Lu, C.T. Liu, and W.D. Porter: Appl. Phys. Lett., 2003, vol. 83 (13), pp. 2581-83.

18. Z.P. Lu, C.T. Liu, J.R. Thompson, and W.D. Porter: Phys. Rev. Lett., 2004, vol. 92 (24), pp. 245503-1.

19. V. Ponnambalam, S. Joseph Poon, and Gary J. Shiflet: J. Mater. Res., 2004, vol. 19 (10), pp. 3046-52.

20. Pearson's Handbook of Crystallographic Data for Intermetallic Phase, P. Villars and L.D. Calvert, eds., ASM INTERNATIONAL, Metals Park, OH, 1985.

21. T.A. Waniuk, R. Busch, A. Masuhr, and W.L. Johnson: Acta Mater., 1998, vol. 46 (15), pp. 5229-36.

22. R. Busch, E. Bakke, and W.L. Johnson: Acta Mater., 1998, vol. 46 (13), pp. 4725-32.

23. F.A. McClintock and S.A. Argon: Mechanical Behavior of Materials, Addison-Wesley, Reading, MA, 1966, p. 273.

24. A. Shamimi Nouri: Ph.D. Thesis, Case Western Reserve University, Cleveland, OH, 2008.

25. Y. Kawamura and A. Inoue: Appl. Phys. Lett., 2000, vol. 77 (8), pp. 1114-16.

26. S. Mukherjee, J. Schroers, Z. Zhou, W.L. Johnson, and W.-K. Rhim: Acta Mater., 2004, vol. 52, pp. 3689-95.

27. J.J. Lewandowski, W.H. Wang, and A.L. Greer: Philos. Mag. Lett., 2005, vol. 85, pp. 77-87. 